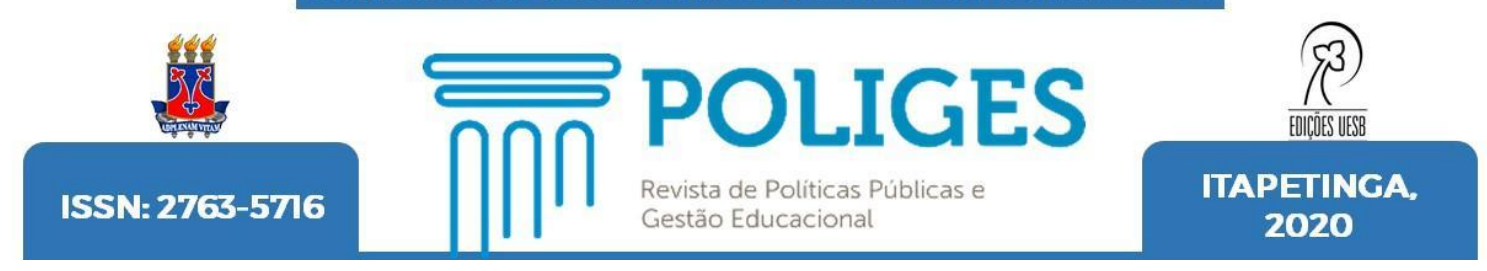

\title{
MONITORAMENTO E AVALIAÇÃO DO PLANO MUNICIPAL DE EDUCAÇÃO DE IGUAÍ/BA: DO GOLPE DE 2016 AO CONTEXTO DA COVID-19
}

MONITORING AND EVALUATION OF THE MUNICIPAL EDUCATION'S PLAN OF IGUAI / BA: FROM THE 2016 COUP TO THE COVID-19'S CONTEXT

\begin{abstract}
SEGUIMIENTO Y EVALUACIÓN DEL PLAN DE EDUCACIÓN MUNICIPAL DEL IGUAI/BA: DEL HIT 2016 AL CONTEXTO COVID-19
\end{abstract}

Edcleide da Silva Pereira Novais ORCID iD: https://orcid.org/0000-0003-4099-0750 Mestre em Educação em Ciências (UNEB) - SMEC/Iguaí/BA - Brasil

Daelcio Ferreira Campos Mendonça

ORCID iD: https://orcid.org/0000-0001-6355-6979 Doutor em Educação (UFBA/FACED) - UESB-Itapetinga) - Brasil

\begin{abstract}
Resumo: A presente pesquisa teve como objetivo central analisar o processo de Monitoramento e Avaliação do Plano Municipal de Educação (PME) de Iguaí/BA e sua relação com o enfraquecimento da legislação educacional voltada para 0 desenvolvimento de políticas públicas educacionais, a partir do Golpe de 2016 até os tempos atuais. Tal discussão foi estabelecida dentro do contexto da Pandemia devido a Covid-19. As principais bases teóricas que sustentam este estudo estão pautadas em: Barreto; Rocha (2020); Brasil (2014); Saviani (2017; 2018); Lombardi (2018); Neta, Cardoso e Nunes (2018). Quanto aos aspectos metodológicos, realizou-se a pesquisa de campo com entrevistas semiestruturadas com integrantes da Equipe Técnica Municipal e com a secretária de educação e pesquisa documental com análise dos Relatórios de Monitoramento e Documento de Avaliação do PME. Sobre a estrutura do texto, inicialmente, apresentam-se alguns aspectos relacionados a esse enfraquecimento e como atingiu o Monitoramento e Avaliação do PME. Em seguida, descreve-se a relevância do Monitoramento e Avaliação do PME de modo geral e como este processo ocorreu em Iguaí/BA. Feita essa exposição, constata-se que existem algumas rupturas e
\end{abstract}


descontinuidades ocorridas nas políticas públicas educacionais desde o Golpe de 2016, agravando-se com a Covid-19. Em relação ao Monitoramento e Avaliação do PME de Iguaí/BA, a Secretaria de Educação precisa encontrar alternativas para que este processo aconteça mesmo com o distanciamento social.

Palavras chave: Golpe de 2016; Monitoramento e Avaliação do PME; Pandemia

Abstract: The main objective of this research was to analyze the Monitoring and Evaluation process of the Municipal Education Plan (PME) in Iguaí / BA and its relationship with the weakening of educational legislation aimed at the development of educational public policies, from the 2016 Coup until the present times. Such a discussion was established within the context of the Pandemic due to Covid-19. The main theoretical bases that support this study are based on: Barreto; Rocha (2020); Brazil (2014); Saviani (2017; 2018); Lombardi (2018); Neta, Cardoso and Nunes (2018). As for the methodological aspects, the field research was carried out with semi-structured interviews with members of the Municipal Technical Team and with the secretary of education and documentary research with analysis of the Monitoring Reports and Evaluation Document of the PME. Regarding t-he structure of the text, initially, some aspects related to this weakening and how it reached the Monitoring and Evaluation of the SME are presented. Then, the relevance of PME Monitoring and Evaluation is described in general and how this process took place in Iguaí / BA. Having made this exposure, it appears that there are some disruptions and discontinuities that have occurred in public educational policies since the 2016 Coup, worsening with Covid-19. Regarding the Monitoring and Evaluation of the PME in Iguaí / BA, the Education Department needs to find alternatives for this process to happen even with social distance.

Keywords: Coup of 2016; Monitoring and Evaluation of EPM; Pandemic

Resumen: El objetivo principal de esta investigación fue analizar el proceso de Monitoreo y Evaluación del Plan Municipal de Educación (PME) en Iguaí / BA y su relación con el debilitamiento de la legislación educativa orientada al desarrollo de políticas públicas educativas, a partir del Golpe de Estado de 2016. hasta la actualidad. Tal discusión se estableció dentro del contexto de la pandemia debido a Covid-19. Las principales bases teóricas que sustentan este estudio se basan en: Barreto; Rocha (2020); Brasil (2014); Saviani (2017; 2018); Lombardi (2018); Neta, Cardoso y Nunes (2018). En cuanto a los aspectos metodológicos, la investigación de campo se realizó con entrevistas semiestructuradas con miembros del Equipo Técnico Municipal y con la secretaría de educación e investigación documental con análisis de los Informes de Seguimiento y Documento de Evaluación del PME. En cuanto a la estructura del texto, inicialmente se presentan algunos aspectos relacionados con este debilitamiento y cómo llegó al Monitoreo y Evaluación de la Pyme. Luego, se describe la relevancia del Monitoreo y Evaluación de PME en general y cómo se llevó a cabo este proceso en Iguaí/BA. Habiendo hecho esta exposición, parece que hay algunas interrupciones $y$ discontinuidades que se han producido en las políticas educativas públicas desde el Golpe de 2016, empeorando con Covid-19. En cuanto al Monitoreo y Evaluación del PME 
en Iguaí/BA, el Departamento de Educación necesita buscar alternativas para que este proceso suceda incluso con la distancia social.

Palabras clave: Soplar de 2016; Monitoreo y evaluación del PME; Pandemia

\section{Introdução}

Dentro da temática desta pesquisa, o processo de Monitoramento e Avaliação do Plano Municipal de Educação (PME), imersa no contexto de crise política e Covid-19, aborda-se o enfraquecimento das políticas públicas educacionais devido ao Golpe de 2016 (SAVIANI, 2018; LOMBARDI, 2018; NETA, CARDOSO e NUNES, 2018), congelamento dos gastos em 2016 pelo governo Temer, no bojo do Programa Ponte para o Futuro 1 e Pandemia 2, bem como suas relações com o declínio da legislação de proteção às políticas públicas educacionais e, assim, a inviabilização do Plano Nacional de Educação (SAVIANI, 2018). Neste contexto, destaca-se o Monitoramento e Avaliação do Plano Municipal de Educação (PME) como um orientador do desenvolvimento de políticas públicas educacionais nos municípios. O PME é um documento normativo que contém ações organizadas por meio de metas e estratégias propostas para a educação. É uma política pública decenal, elaborada para atender aos pressupostos da Lei $n^{\circ}$ 13.005, de 25 de junho de 2014, referente ao Plano Nacional de Educação (PNE), deve ser elaborada com participação da comunidade escolar e da sociedade civil, através de Conferências Municipais e Audiências públicas. ${ }^{1}$

Tanto o PNE quanto o PME são bússolas orientadoras das políticas educacionais, entretanto, mesmo com toda a importância que trazem foram deixados à margem das políticas públicas desde o golpe de 2016. Após o golpe houve uma sucessão de retrocessos no âmbito nacional, estadual e municipal. O governo Temer (31 de agosto de 2016 a 31 de dezembro de 2018) foi marcado pelo congelamento dos recursos da Educação por 20 anos, 366 deputados votaram a favor do chamado Projeto de Emenda Complementar - PEC 241. Com a substituição de Temer por Bolsonaro nada melhorou, as

\footnotetext{
${ }^{1}$ Este Programa é uma política de governo do Partido do Movimento Democrático Brasileiro, lançado em 2015. Justificado pela necessidade de "preservar a economia brasileira e tornar viável o seu desenvolvimento, devolvendo ao Estado a capacidade de executar políticas sociais que combatam efetivamente a pobreza e criem oportunidades para todos" (TEMER, 2015, p. 1). A recusa da presidenta Dilma Rousseff em colocar o Programa em prática culminou na sua saída do poder, como relata Michel Temer no discurso realizado para empresários e investidores nos Estados Unidos, no dia 21 de setembro de 2016. Esse fato foi publicado no site Carta Capital, no dia 23/09/2016. Com este Programa houve o congelamento dos gastos públicos, por meio da PEC 241/55 e redução do tamanho do Estado. Dando início ao enfraquecimento do Estado e fortalecimento do neoliberalismo, baseado principalmente no Estado Mínimo (mínimo para os gastos sociais, mas máximo para o controle, fascismo e ditadura).
} 
trocas de ministros e escândalos que envolvem seu governo, fez com que a educação estagnasse. Se não bastassem os problemas causados por uma gestão de incertezas, em 2020, o mundo foi acometido por uma pandemia causada pelo Novo Coronavírus ${ }^{2}$, uma pandemia que contaminou em massa a população e paralisou a educação escolar.

Diante dessa complexidade, realizamos esta pesquisa que teve como objetivo analisar o processo de Monitoramento e Avaliação do Plano Municipal de Educação (PME) e sua relação com o enfraquecimento da legislação educacional voltada para o desenvolvimento de políticas públicas educacionais, a partir do Golpe de 2016 até os tempos atuais.

A partir dos estudos teóricos que fundamentam as políticas educacionais e análise do contexto atual, buscou-se responder às seguintes questões de pesquisa: como o município de Iguaí está se adequando para garantir o Monitoramento e avaliação do PME em tempo de Covid-19? Quais medidas foram tomadas pela Secretaria de Educação para garantir que as estratégias do PME sejam cumpridas, mesmo com a crise econômica atual e durante a pandemia? Quais as concepções dos integrantes da Equipe Técnica Municipal e da secretária de educação sobre a importância do Monitoramento e Avaliação do PME?

Em busca por respostas a estes questionamentos, apresentam-se os objetivos específicos:

i) Investigar os desafios enfrentados pela Secretaria Municipal de Educação para atender ao Monitoramento e Avaliação do PME em tempo de Covid-19;

ii) Descrever alguns retrocessos que envolvem a legislação educacional, causados pelas mudanças de governo e os impactos nas políticas educacionais, a partir do Golpe de 2016; iii) Investigar as concepções dos integrantes da Equipe Técnica Municipal e da secretária de educação sobre a importância do Monitoramento e Avaliação do PME, bem como as ações para materialização das estratégias.

\footnotetext{
${ }^{2}$ O primeiro caso confirmado no Brasil foi em 26 de fevereiro de 2020. No dia 17 de março de 2020 foi determinado que todas as escolas e demais estabelecimentos de ensino das redes pública e privada fossem fechadas devido ao avanço do Coronavírus. No dia 16 de junho de 2020 , por meio da Portaria $\mathrm{n}^{\circ}$ 544, autorizou-se a substituição das aulas presenciais por aulas em meios digitais enquanto durar a situação de pandemia do Novo Coronavírus - COVID-19 (BRASIL/DOU, 2020).
} 
Metodologicamente, utilizou-se da pesquisa qualitativa para analisar o processo de Monitoramento e Avaliação do PME, enquanto ferramenta para melhoria das ações do Plano. A pesquisa qualitativa favorece a ampliação do conhecimento sobre a temática, pois tem o ambiente natural e os sujeitos como fonte direta dos dados (BOGDAN; BIKLEN, 1994), aproximando o investigador do objeto investigado.

De natureza exploratória, desenvolveu-se a pesquisa de campo com integrantes da Equipe Técnica Municipal (ETM) (composta por 11 integrantes) e a secretária de educação de Iguaí/BA. Realizaram-se entrevistas semiestruturadas ${ }^{3}$ com a ETM no grupo focal ${ }^{4}$ e com a secretária, individualmente, esse procedimento foi fundamental para entender como ocorre o Monitoramento e Avaliação, bem como conhecer os entraves, potencialidades e desafios deste processo em tempo de crise política e Covid-19.

Além dos dados primários houve também a coleta de dados secundários por meio da análise documental dos relatórios de Monitoramento e Documentos de Avaliação do PME de Iguaí/BA, desde 2017, quando iniciou o acompanhamento das metas e estratégias.

A discussão dos resultados foi realizada por meio das categorias: Potencialidades e desafios do Monitoramento e Avaliação do PME em Iguaí/BA e o Enfraquecimento do Monitoramento e Avaliação e descontinuidade das políticas públicas devido ao Golpe de 2016 e a Covid-19. A análise é com base nos referenciais adotados na pesquisa: Barreto; Rocha (2020); Brasil (2014); Saviani (2017; 2018); Lombardi (2018); Neta, Cardoso e Nunes (2018). Foram apresentados referenciais teóricos que tratam do enfraquecimento das políticas públicas devido ao Golpe de 2016, além dos Documentos de orientações publicados pelo Ministério da Educação e referenciais que tratam do processo de Monitoramento e Avaliação do PME, bem como referente a Covid-19.

\footnotetext{
${ }^{3}$ As entrevistas semiestruturadas foram realizadas na Secretaria Municipal de Educação, respeitando o distanciamento social estabelecido pelas autoridades locais e órgãos da saúde.

${ }^{4}$ Empregou essa técnica nesta pesquisa, pois "permite que o pesquisador compreenda diferenças e divergências, contraposições e contradições nos discursos dos sujeitos" (MENDONÇA; GOMES, 2017, p. 3). Além de facilitar a compreensão que os participantes têm acerca das potencialidades e desafios do Monitoramento e Avaliação do PME.
} 


\section{O enfraquecimento do processo de Monitoramento e Avaliação de Políticas Públicas no Brasil após o Golpe de 2016 e Covid-19}

Este tópico busca, em pequena escala, apresentar o conceito de políticas públicas, especialmente as políticas públicas educacionais, bem como o enfraquecimento do processo de Monitoramento e Avaliação das políticas educacionais causado pelas trocas de governo, principalmente o afastamento da presidenta Dilma Rousseff, em 2016, por meio de impeachment, fato que alguns autores denominam de Golpe de Estado (ÁVILA, 2018; KRAWCZYK e LOMBARDI, 2018; SAVIANI, 2017, 2018). Para entender melhor os impactos pós-golpe, recorre-se a manifestação ocorrida em 2013, precedendo ao golpe de 2016. Por fim, pontua-se algumas rupturas e descontinuidades ocorridas nas políticas educacionais, com vista no processo de monitoramento e avaliação dessas políticas, a partir das decisões tomadas por Michel Temer, sucessor de Dilma Rousseff.

Para entender melhor o tema exposto neste tópico, explicar-se-á em poucas palavras o que são políticas públicas e sua importância para o desenvolvimento da sociedade. Políticas públicas são programas e ações do Estado para atender as necessidades da população e foram criadas para amenizar e/ou sanar situações problemas em que os cidadãos estão imersos, envolvendo todos os setores e áreas da sociedade independente da posição social e/ou econômica que está inserida.

As políticas públicas seguem um paradigma ideológico, administrativo e econômico, podendo sofrer diversas alterações tanto avançando quanto regredindo, a depender da gestão governamental. De acordo com Rua (2014), políticas públicas são ações estrategicamente selecionadas para implementar as decisões tomadas. Ainda segundo a autora, as políticas públicas compreendem "o conjunto das decisões e ações relativas à alocação imperativa de valores envolvendo bens públicos" (p. 19). No âmbito das políticas públicas, várias políticas educacionais foram criadas ao longo dos anos no Brasil, algumas marcadas por avanços e retrocessos diante das trocas de governo. Tantas idas e vindas promoveram a descontinuidade de suas ações, mesmo sendo um Projeto de Lei. Oliveira (2010), em um sentido mais restrito, afirma que políticas educacionais nada mais são do que um conjunto de ações para a educação escolar. 
Antes de analisar o processo de descontinuidade das políticas educacionais, será apresentado o cenário político (2004 - 2011) que vivia o Brasil antes do golpe de 2016, na visão do economista Róber Iturriet Avila (2018), em uma palestra intitulada "Rupturas de política econômica e o golpe de 2016", no IFCH - Universidade Federal do Rio Grande do Sul sobre a destituição de Dilma Rousseff, ocorrida em 04/04/2018. Ávila (2018) sinaliza que o país tinha "condições externas excepcionais (melhoria dos termos de intercâmbio); crescimento econômico consistente; aumento do emprego (redução do desemprego); elevação das reservas internacionais; elevação real do salário mínimo real e do salário médio real; redução das desigualdades de renda". Para ilustrar esses elementos, o economista apresenta alguns gráficos, dos quais, apresentam-se dois para justificar as rupturas na economia brasileira que sobrevieram após 2016.

Ávila (2018) trouxe vários elementos que mostraram um avanço significativo na situação econômica e política entre 2004 e 2013 (período governado por Lula e Dilma Rousseff). Entretanto, essa diminuição nas taxas não agradou os endinheirados, "daí, o cultivo do ódio da classe média contra o PT, ódio incentivado pela mídia que diariamente, repetindo à exaustão, se dedica a esmiuçar denúncias não comprovadas contra Dilma, Lula e o PT" (SAVIANI, 2017, p. 216).

A vinculação de tantas denúncias motivou a população ir às ruas em 2013 , protestar contra o governo de Dilma Rousseff. Esta manifestação popular contribuiu com a queda da popularidade da presidenta, como analisa o sociólogo Felipe Floresti, na Revista Galileu, em 2018. Desde então, iniciou uma forte crise econômica e política no Brasil, vivida até os dias de hoje, como afirma Fernanda Odilla, em uma reportagem no site da BBC News Brasil em Londres, no dia 09 de junho de 2018. De certo, que o movimento político de 2013 deu início a uma luta diária para forçar a saída da presidenta Dilma Rousseff do poder, fato ocorrido em 2016.

A saída de Dilma Rousseff do poder em 2016 foi caracterizada como Golpe de Estado, pois organizaram um impeachment para derrubar um governo eleito democraticamente, sem as devidas investigações e comprovação de crime (SAVIANI, 2017; 2018). O autor justifica sua fala afirmando que a maneira como o julgamento da presidenta foi conduzido feriu a Constituição Federal. A Constituição prevê o impeachment, para tanto é necessário que haja crime de responsabilidade, o que segundo ele, não conseguiram comprovar. Assim, o Ato iniciado em 17 de abril pela 
Câmara dos Deputados e concretizado pelo Senado em 31 de agosto de 2016, em nome do combate à corrupção, "é, mesmo, Golpe de Estado, pois a Constituição não será respeitada, mas violada. E nenhuma das alegações apresentadas para justificar o impeachment caracteriza crime de responsabilidade" (SAVIANI, 2017, p 217). Lombardi e Lima (2018) diz que a saída forçada da presidenta foi uma contrarrevolução com características históricas: antinacional, antipopular, antidemocrático e pró-imperialista.

A partir do Golpe de 2016, o Brasil vive um enorme retrocesso político desencadeado pela saída de Dilma, a prisão de Lula e a estratégia de campanha para eleger Bolsonaro, planejada com a assessoria do marqueteiro de Trump, Steve Bannon (SAVIANI, 2018).

Neste contexto de retrocesso político e econômico vivido pela sociedade devido ao golpe que nocauteou a democracia brasileira, várias áreas foram afetadas, destaca-se a educação escolar, mas, precisamente, as políticas públicas educacionais com inúmeras rupturas e interrupções de suas ações.

Para entender melhor o que está acontecendo na educação atual, analisar-se-á a partir do golpe de 2016, que instituiu Michel Temer como presidente da república. Segundo Orso (2017, p. 233), houve uma sucessão de outros golpes, como a "PEC 241/55, que congelou os salários por 20 anos, na Reforma do Ensino Médio, da Previdência, na terceirização, na Reforma Trabalhista e Política, [...], configuram-se como um ataque sem precedente contra a classe trabalhadora".

De certo que o novo governo instituído por Michel Temer iniciou com medidas que trouxeram retrocessos no Plano Nacional de Educação (PNE), aprovado pela Lei n. 13.005, em 25 de julho de 2014. O PNE é um instrumento de planejamento que orienta a execução e o aprimoramento de políticas públicas educacionais (BRASIL, 2014). As ações do Plano contribuem para melhorar e qualificar a educação escolar. Após aprovação do PNE, estados e municípios elaboraram e implementaram seus Planos, em consonância com o Plano Nacional.

Com o intervalo de um ano iniciaram o processo de Monitoramento e Avaliação das metas e estratégias para analisar avanços e retrocessos das ações. Ressalta-se que até 2018, o Monitoramento e Avaliação das metas foram orientados pela esfera nacional, a partir de 2019 essa responsabilidade ficou a cargo dos estados, esta nova 
mudança faz parte da troca de governo que ocorreu em 2018, através das eleições presidenciais.

No PNE foi previsto um aumento para $10 \%$ do PIB para na educação, entretanto, com o congelamento de verbas por 20 anos, através da Medida Provisória inviabilizou algumas metas, enfraquecendo o processo de monitoramento e avaliação. Neste sentido, Saviani (2018) é enfático ao afirmar que o PNE se tornou letra morta, "pois várias de suas metas já venceram sem serem atingidas e as que ainda não venceram não têm mais a mínima chance de se viabilizar" (p. 38). Corroborando, Lombardi e Lima (2018) ressaltam que o Golpe de Estado, ocorrido em 2016, tornou as conquistas sociais letra morta, inclusive o PNE. Aranda, Rodrigues e Militão (2020) afirmam que em um cenário de inúmeros retrocessos políticos "a efetiva materialização do PNE 2014-2014 encontra-se significativamente comprometida" (p.6).

Com a descaracterização do PNE, o processo de Monitoramento e Avaliação dos Planos Estaduais e Municipais ficou enfraquecido perdendo o seu objetivo maior que é uma educação de qualidade com um ensino igualitário e inclusivo. A diminuição de verba inviabilizou muitas metas, impossibilitando o alcance das estratégias traçadas.

Salienta-se que é a partir do Monitoramento e Avaliação que a comunidade escolar e sociedade civil propõem ações para melhoria da educação escolar, mas algumas dessas ações ficaram praticamente impossíveis causando desmotivação entre os educadores. Piorando a situação, em 2020, o mundo foi parado por uma pandemia, denominada de Covid-19, por meio da qual houve mudanças drásticas no modo de vida das pessoas, o ir e vir deixou de existir porque o medo tomou conta da população.

Com o aumento de casos no Brasil e sem alternativas, no dia 16 de março o governador Rui Costa decidiu suspender as aulas tanto na rede pública quanto particular por meio do Decreto Estadual № 19.529, o objetivo deste ato é evitar a contaminação em massa da população. Desde então, os municípios vêm buscando soluções para amenizar o impacto desastroso da pandemia no ensino. Uma das soluções encontradas foi a adoção de atividades pedagógicas não presenciais mediadas por tecnologias digitais, por meio do ensino remoto emergencial. É um momento delicado que precisa de adequações em toda a rede de ensino, pois nem todos os alunos dispõem de internet e computador para os estudos. Como alternativa 
para amenizar o impacto negativo da pandemia na educação, no dia 28 de abril, o Conselho Nacional de Educação (CNE), por meio do Parecer 05/2020, publicou orientações para a reorganização do Calendário Escolar e da possibilidade de cômputo de atividades não presenciais para fins de cumprimento da carga horária mínima anual, em razão da Pandemia da Covid-19.

Mesmo com a pandemia os Planos de Educação continuam ativos, pois é uma obrigatoriedade prevista na Constituição Federal/88, no Artigo 214 e na Lei de Diretrizes e Bases da Educação/96 em seu Artigo 9, assim, o próximo tópico busca apresentar a relevância do Monitoramento e Avaliação do Plano Municipal de Educação para a implementação de políticas educacionais.

\section{Plano Municipal de Educação: relevância, Monitoramento e Avaliação}

O Plano Municipal de Educação (PME) é um documento legal e estratégico, que contém 20 metas com duração de dez anos, aprovado por meio de Projeto de Lei pela Câmara Municipal de Vereadores, que define as Políticas Públicas para a educação do município. Este Plano deve está articulado com o Plano Nacional de Educação (PNE) e alinhado ao Plano Estadual de Educação ${ }^{5}(\mathrm{PEE})$.

Conforme o Caderno de Orientações para Monitoramento e Avaliação dos Planos Municipais de Educação, publicado em 2016, o PNE e os Planos de educação do estado e do município devem formar um conjunto coerente, integrado e articulado para que os direitos dos cidadãos sejam garantidos e o Brasil tenha educação com qualidade para todos. Sendo o PME um documento criado para regularizar a educação ele é composto de:

De estratégias e de políticas de educação que inclua a intenção de uma constante avaliação, à luz da Constituição Federal e Lei Orgânica do Município, observando os princípios estabelecidos na Lei das Diretrizes e Bases da Educação Nacional, interagindo com as metas definidas no Plano Nacional de Educação - Lei n 10.172/2001, e no Plano Estadual de Educação (BRASIL/MEC, 2005, p. 25).

O Caderno de Orientações afirma que para alcançar o sucesso esperado é necessário que haja legitimação no processo de elaboração do PME (BRASIL, 2016).

\footnotetext{
${ }^{5}$ Na Bahia, a Lei 13.559, de 11 de maio de 2016.
} 
Essa legitimidade só é possível se o monitoramento de seus resultados impulsionar a sua concretização e atender as necessidades dos sujeitos.

Para a elaboração do Plano é necessário realizar um diagnóstico das necessidades educacionais do município, a partir daí definir as estratégias para atendê-las. De posse dos dados levantados no diagnóstico, inicia-se a elaboração do Documento-Base para um amplo debate, nesta fase é importante que a equipe responsável fique atenta às sugestões e críticas, em seguida redigir-se-á o Projeto de Lei a ser encaminhado à Câmara de Vereadores para apreciação e aprovação.

Com o Plano Municipal de Educação ativo, inicia-se o Monitoramento contínuo e Avaliação periódica de seu desenvolvimento. O Monitoramento é realizado anualmente e a Avaliação de dois em dois anos, tanto um quanto o outro exige mobilização e ampla participação da comunidade escolar e sociedade civil por meio de Audiências Públicas e Conferências, "[...], a fim de que este plano se constitua em efetiva política de Estado para a educação" (DOURADO, 2017, p. 19).

Para Menezes (2019, p. 19), os sistemas de Monitoramento e Avaliação se constituem um "conjunto de atividades, articuladas, sistemáticas e formalizadas, de produção, registro, acompanhamento e análise crítica de informações geradas na gestão de políticas públicas". Essas atividades possibilitam conhecer os entraves que impedem o sucesso de uma política pública e contribui para avaliar o efeito de suas ações, auxilia a gestão a traçar medidas corretivas quando necessário.

O Monitoramento acontece por meio da observação, tornando públicas as informações sobre o progresso das metas. Já a Avaliação objetiva analisar se as ações em andamento ou alcançadas estão atendendo aos objetivos propostos, bem como orientando a tomada de decisões (BRASIL, 2016). Portanto, o Monitoramento e Avaliação:

Deve significar uma oportunidade de melhorar a qualidade técnica do diagnóstico, de ampliar a participação social e de qualificar ano a ano a execução das metas. Deve ser entendido como exercício contínuo de aproximação da gestão ao desejo da sociedade, em um trabalho coletivo e democrático, em que o estudante é o grande beneficiado (BRASIL, 2016, p. 4).

No Monitoramento e Avaliação das metas e estratégias, são levados em conta dados disponibilizados pelo Instituto Brasileiro de Geografia e Estatística (IBGE), pela Pesquisa Nacional de Amostra de Domicílio (PNAD), pela Secretaria de Articulação com o Sistema de Ensino (SASE), além de dados adquiridos por meio de minicenso 
realizado pela Equipe Técnica Municipal (ETM), bem como a análise dos indicadores, investigando se houve avanço ou não nas ações realizadas pelo município para atender cada meta e traçar medidas corretivas para o alcance de cada uma. $O$ acompanhamento contínuo do PME é organizado pela Equipe Técnica Municipal, que cataloga os dados e disponibiliza para os envolvidos na educação municipal. Ressalta-se que a ETM é nomeada por meio de decreto ou Portaria publicada previamente.

Assim, o processo de Monitoramento e Avaliação do Plano Municipal de Educação é uma ferramenta essencial para a implementação de políticas públicas educacionais, pois a partir da análise das estratégias é possível descobrir lacunas, corrigir erros e propor novas ações que atendam as necessidades da sociedade.

Considerando a importância do Monitoramento e Avaliação dos Planos para a implementação de políticas educacionais, o próximo tópico descreve como esta ferramenta tem sido usada para garantir uma educação de qualidade no município de Iguaí/BA. Esta análise foi realizada tendo como base os relatórios de Monitoramento e Documentos de Avaliação do PME produzidos pelo município desde 2017, ano em que iniciou a análise das metas e estratégias.

\section{O Plano Municipal de Iguaí/BA: Monitoramento e Avaliação}

O Monitoramento e Avaliação do Plano Municipal de Educação (PME) é um processo previsto no Artigo $5^{\circ}$ do Plano Nacional de Educação (PNE), Lei $n^{\circ}$ 13005/2014. A partir desta determinação este processo é realizado anualmente pelas esferas nacional, estadual e municipal, para entender como acontece essa ação em Iguaí/BA, este tópico objetiva descrever como ocorreu este processo desde 2017, quando iniciou. Como visto, o PME é construído em consonância com o PNE e embora as metas que o compõem sejam nacionais, a concretização é onde o sujeito vive.

O Plano Municipal de Educação de Iguaí/BA é um Projeto de Lei aprovado pela Câmara Municipal de Vereadores, por meio da Lei $n^{\circ} 251$, de 16 de Junho de 2015. O PME foi elaborado a partir de um processo democrático e participativo com membros de diferentes setores da sociedade civil, com a realização de várias reuniões para traçar as 
Diretrizes e estratégias a serem executadas no período de 10 (dez) anos, garantindo assim a qualidade na construção e implementação do Plano. Neste período ainda não existia o Fórum Municipal de Educação, criado em 2017 com o início do processo de Monitoramento e Avaliação.

Antecedendo ao processo de Monitoramento e Avaliação do PME, foram realizadas reuniões para constituição do Fórum Municipal de Educação (FME), pela Equipe Técnica e Comissão de Coordenação. Ressalta-se que em 2019, A Equipe Técnica e Comissão de Coordenação se fundiram formando a Equipe Técnica Municipal. Neste mesmo ano as orientações, que antes eram feitas a nível nacional, foram realizadas pela Secretaria do Estado da Bahia.

No período do Monitoramento e Avaliação do PME ocorreram várias reuniões com a Equipe Técnica Municipal e com o Fórum Municipal de Educação (FME), nas quais foram realizadas as seguintes atividades: estudo do plano a partir de leitura das metas, estratégias e indicadores; construção de instrumentos para coletar os dados que subsidiaram o levantamento das informações do monitoramento; análise dos avanços e entraves de cada meta; realização de mini audiências nas escolas para colher sugestões da comunidade escolar; encaminhamento dos registros de cada etapa ao Dirigente Municipal de Educação para validar o trabalho; realização da Conferência Municipal de Educação e elaboração do relatório. Os dados foram adquiridos por meio do Censo Escolar, Sistema Integrado de Monitoramento, Execução e Controle (SIMEC), Secretaria Municipal de Educação e Saúde.

Vale ressaltar que no PME de Iguaí/BA, ficou estabelecido que o acompanhamento e avaliação das ações devem acontecer de maneira contínua "o que certamente fortalecerá as decisões que devam ser tomadas para correção de rumos e busca dos necessários suportes para otimização do Plano" (PME/IGUAí, 2015, p. 94). Corroborando, Neto, Castro e Garcia (2016) afirmam que o acompanhamento contínuo das ações planejadas é uma necessidade, pois possibilita identificar dificuldades e propor ações para superá-las, além de contribuir para a análise dos encaminhamentos realizados.

Entretanto, Silva (2001) alerta que Monitorar e Avaliar são processos distintos, porém com uma relação direta. O Monitoramento capta as informações que deverão 
ser analisadas durante a Avaliação, para que novas ações sejam planejadas para garantir o cumprimento das metas estabelecidas nas políticas públicas. Portanto:

O monitoramento fornece informação a respeito do estágio de desenvolvimento de uma política, um programa ou um projeto em dado momento, em relação às respectivas metas e resultados. Já a avaliação evidencia o porquê das metas e dos resultados estarem ou não sendo atingidos (BORGES, 2017, p. 46).

Dada a importância de monitorar e avaliar uma política pública para que tenha êxito, anualmente este monitoramento é realizado em Iguaí/BA e desde o primeiro Monitoramento ocorrido em 2017 e o último em 2019, percebe-se que permanecem os mesmos problemas em relação a obtenção de dados, pois o banco de dados encontra-se desatualizado e não corresponde à realidade vivida, o que dificultou a sua mensuração. A partir da análise e discussões das metas, estratégias e indicadores, constatou-se a necessidade de rever algumas metas que estavam em dissonância com o Plano Nacional de Educação e algumas estratégias que não estavam dando conta de cumprir o propósito para o qual foram determinadas. Para que o PME esteja em consonância com o PNE foram construídas notas técnicas que serviram de base para elaborar um Projeto de Lei que foi enviado para a Câmara de Vereadores e aprovado em dezembro de 2019.

Com o avanço da pandemia, o município de Iguaí/BA suspendeu as aulas para evitar a proliferação do vírus, como mostra o Artigo $1^{\circ}$ do Decreto 004/2020 de 18 de março de 2020:

Art. $1^{\circ}$ - Ficam suspensas no âmbito do Município de Iguaí, pelo prazo de 30 (trinta) dias, a partir de 19 de Março do corrente ano, as aulas da rede municipal de ensino, bem como as aulas de todas as instituições de ensino privadas, podendo ser prorrogada tal suspensão.

Esta suspensão durou até o dia 31 de julho quando foi publicado o Decreto $\mathrm{N}^{\circ}$ 50/2020, que dispõe sobre a realização de atividades pedagógicas não presenciais (remotas), no âmbito da Rede Pública Municipal de Educação, como medida temporária e emergencial de prevenção de contágio pelo Coronavírus (Covid-19). No Artigo $1^{\circ}$ do referido Decreto continua a suspensão das aulas presenciais dando lugar às aulas remotas, como determina o Artigo $2^{\circ}$ :

Art. $2^{\circ}$ Fica determinado, a partir do dia 3 de agosto de 2020, no âmbito da Rede Pública Municipal de Educação, a implementação da realização de atividades remotas (atividades não presenciais), conforme 
regulamentação efetuada pela Secretaria Municipal de Educação e aprovação realizada pelo Conselho Municipal de Educação.

A suspensão das aulas por conta da Covid-19 paralisou a educação escolar, comprometendo o Monitoramento e Avaliação do Plano, mesmo com o retorno no dia 03 de agosto o município não conseguiu se adequar para cumprir o processo. Então, a Secretaria Municipal de Educação enviou um ofício à Secretaria de Educação do Estado informando a inviabilidade do Monitoramento e Avaliação, explicando as razões pelas quais não é possível realizá-los em 2020.

Tendo em vista a importância do PME, o próximo tópico buscou discutir as consequências da crise política e econômica, assim como a Covid-19 para o processo de Monitoramento e Avaliação das metas e estratégias na elaboração e execução de políticas públicas educacionais.

\section{Potencialidades e desafios do Monitoramento e Avaliação do PME em Iguaí/BA.}

De acordo com os estudos realizados e entrevistas semiestruturadas, constatou-se que o Monitoramento e Avaliação são essenciais para o desenvolvimento das políticas educacionais municipais, pois através das análises realizadas é possível implantar medidas corretivas em relação às decisões tomadas anteriormente.

Porém, nem sempre o processo de Monitoramento e Avaliação do Plano Municipal é levado a sério pela comunidade escolar. Segundo um integrante da Equipe Técnica Municipal (ETM), "mesmo com o apoio da Secretaria de Educação, a maioria dos profissionais da educação não se envolve no processo, ficando a responsabilidade para apenas dois ou três educadores" (Integrante 5). Essa postura dos educadores contradiz o que apresenta o Caderno de Orientações para Monitoramento e Avaliação dos Planos Municipais de Educação publicado pelo Ministério da Educação, o Caderno afirma que o processo de Monitoramento contínuo e Avaliação periódica "deve significar uma oportunidade de melhorar a qualidade técnica do diagnóstico, de ampliar a participação social e de qualificar ano a ano a execução das metas" (BRASIL, 2014, p. 4).

Acerca da participação social, Neto, Castro e Garcia, (2016) afirmam que: 
A participação social é essencial na avaliação do cumprimento das metas do PME porque possibilita o desenvolvimento de análises quantitativas e qualitativas da situação educacional da rede de ensino em relação às metas propostas (NETO; CASTRO; GARCIA, 2016, p. $59)$.

Esta participação deve ocorrer desde a elaboração do Plano até a avaliação das ações, assim todos sentirão que fazem parte e têm responsabilidade igual a todos, independente do cargo ou função que atua. Entretanto, Lombardi e Lima (2018) alertam que as políticas educacionais pós Golpe de 2016 têm desconstruído a capacidade crítica para a tomada de decisões, promovendo o imobilismo e a negação dos indivíduos em relação a sua participação na elaboração e implementação de políticas educacionais.

O Monitoramento e Avaliação de uma política são indispensáveis para o seu sucesso. Aranda, Rodrigues e Militão (2020) afirmam que a ausência de práticas avaliativas "contribuem negativamente para o êxito de uma política pública" (p. 3). Os atos de Monitorar e Avaliar se completam com o objetivo de apontar lacunas e possíveis mudanças no desenvolvimento do Plano, tornando-o flexível para atender as necessidades da sociedade (BRASIL, 2014).

Acompanhar e fiscalizar as estratégias do PME possibilita "fortalecer o próprio Plano, dando a devida importância que ele traz. Contribuindo para a visibilidade das metas e estratégias para que todos tenham conhecimento", como pontua o Integrante 2. Esta ação assegura transparência e controle social do Plano (BRASIL, 2014).

Em relação aos desafios relacionados ao processo de Monitoramento e Avaliação do PME, pontua-se inicialmente a desatualização dos dados, mencionado no Relatório de Monitoramento de 2019 e reafirmado pela Integrante 7. A referida Integrante relatou: "percebemos a divergência nas informações quando realizamos o minicenso".

Outro desafio mencionado tanto por integrantes da Equipe Técnica Municipal (ETM) quanto pela secretária de educação está relacionado aos recursos financeiros, a Integrante 11 assinala: "a Lei Orçamentária Anual precisa ser construída tendo como base o PME porque analisando a mesma percebemos que as verbas estão mal distribuídas e algumas não são contabilizadas para o fim a que foi destinada". A secretaria de educação menciona os recursos financeiros quando afirma que "ainda têm muitas coisas a serem feitas, mas com a redução de investimento desde a saída da presidenta Dilma Rousseff tem ficado cada vez mais difícil cumprir as metas". Uma 
questão que chamou a atenção no Documento de Avaliação de 2019 foi uma observação colocada pela ETM: "o setor responsável pelo financeiro do município não disponibilizou os dados solicitados" (Documento de Avaliação/2019 de Iguaí/BA, p. 6). Para que o PME tenha eficácia é importante a união de todos os setores porque um depende do outro.

A ausência de conhecimento do Plano por parte dos educadores se constitui como um grande desafio, além de dificultar a sua evolução, como traz outro Integrante da ETM: "boa parte dos educadores não conhecia o PME em 2017, outros não dão a devida importância, o que dificultou e dificulta a participação" (Integrante 1). Aproveitando a oportunidade da fala do Integrante 1 mencionada acima, foi pedido que eles relatassem as principais dificuldades encontradas durante o Monitoramento e Avaliação, o Integrante 6 respondeu: pouco tempo para a construção do Relatório de Monitoramento, falta de envolvimento das pessoas, ausência de parceria intersetorial, ausência de investimentos para cumprir as estratégias. Estas dificuldades pontuadas pelo Integrante 6 também estão descritas no Relatório de 2019 na página 5.

Como vimos, o Monitoramento e Avaliação do PME é fundamental para dar transparência e legitimidade às metas, além de envolver todos os cidadãos do município na execução das estratégias. Entretanto, são necessárias algumas medidas corretivas para facilitar o bom desenvolvimento das ações e atingir o objetivo para o qual o Plano foi criado. Os inúmeros desafios enfrentados no Monitoramento e Avaliação promovem enfraquecimento e descontinuidade das políticas públicas educacionais, como será apresentado no próximo tópico.

\section{Enfraquecimento do Monitoramento e Avaliação e descontinuidade das políticas públicas devido ao Golpe de 2016 e a Covid-19}

De acordo com as entrevistas semiestruturadas, o Golpe de 2016 e a pandemia provocaram o enfraquecimento do Monitoramento e Avaliação do Plano Municipal de Educação, além da descontinuidade de suas ações, como exemplo tem-se o Plano Municipal de Educação (PME).

Quando questionada como tem sido o Monitoramento e Avaliação do PME em tempo de crise econômica devido ao Golpe de 2016, a secretaria de educação sinaliza: "percebi que muitos recursos diminuíram limitando a execução de algumas 
metas. O município não sentiu muito porque recebemos os precatórios, mas quando acabar não sei como será".

A mesma questão foi feita a Equipe Técnica Municipal (ETM), um integrante respondeu: "difícil (risos) porque as verbas foram congeladas por Michel Temer e sem dinheiro nada pode ser feito" (Integrante 1). Saviani (2017) discutindo a questão do Golpe de 2016 e o papel da educação na resistência e transformação da situação de crise que o país está imerso, pontua que cabe a educação "lutar para transformar a situação atual debelando a crise e assegurando às novas gerações uma formação sólida que Ihes possibilite o pleno exercício da cidadania" (SAVIANI, 2017, p. 38). O referido autor salienta que por conta do Golpe a educação está diante de um retrocesso.

Tal retrocesso implica na descontinuidade das políticas públicas que a cada troca de governo novos projetos são elaborados deixando os existentes inconclusos.

Outra situação que está em evidência é o impacto da pandemia na educação, consequentemente nas políticas educacionais. Em relação ao PME em tempo de pandemia, foi questionado sobre as medidas adotadas para garantir o Monitoramento e Avaliação, a secretária de educação pontuou:

Infelizmente não faremos o Monitoramento e Avaliação este ano devido a ausência de algumas pessoas porque apresentam comodidades e sem aulas presenciais ficou ainda pior. A solução foi iniciar o ensino remoto, solução desafiadora para a nossa rede (Entrevista Secretária de Educação, 12/10/2020).

Barreto e Rocha (2020), analisando alguns desafios da educação em tempo de pandemia, ressaltam que não será fácil a volta à normalidade da vida social, educacional e econômica, precisará de soluções alternativas. As autoras sugerem a tecnologia como uma opção, pois se constitui um espaço de luta e transformação da realidade atual.

Analisando as legislações nacionais e estaduais para a educação em tempo de Covid-19, observou-se que não há uma Lei específica que atenda ao Monitoramento contínuo e Avaliação periódica das políticas públicas educacionais, como mostra o quadro abaixo.

Tabela 1: Legislação COVID-19 - Educação 


\begin{tabular}{|c|c|}
\hline $\begin{array}{l}\text { Parecer CNE/CP no } 11 / 2020 \text { de } \\
\text { 07/07/2020. }\end{array}$ & $\begin{array}{l}\text { Orientações Educacionais para a } \\
\text { Realização de Aulas e Atividades } \\
\text { Pedagógicas Presenciais e não Presenciais } \\
\text { no contexto da Pandemia. }\end{array}$ \\
\hline Parecer CNE/CP nº 15 de 06/10//2020. & $\begin{array}{l}\text { Diretrizes Nacionais para a implementação } \\
\text { dos dispositivos da Lei } n^{\circ} 14.040 \text {, de } 18 \text { de } \\
\text { agosto de } 2020 \text {, que estabelece normas } \\
\text { educacionais excepcionais a serem } \\
\text { adotadas durante o estado de calamidade } \\
\text { pública reconhecido pelo Decreto Legislativo } \\
\mathrm{n}^{\circ} 6 \text {, de } 20 \text { de março de } 2020 \text {. }\end{array}$ \\
\hline Resolução CEE N. ${ }^{\circ} 50$ de 09/11/2020. & $\begin{array}{l}\text { Validação do regime especial de atividades } \\
\text { remotas é publicada pelo Conselho Estadual } \\
\text { de Educação. }\end{array}$ \\
\hline \multirow[t]{2}{*}{ Parecer CEE nº 99/2020 de 10/11/2020 } & $\begin{array}{l}\text { Normatiza procedimentos para a } \\
\text { integralização da carga horária mínima do } \\
\text { ano letivo afetado pelo estado de } \\
\text { calamidade pública e para a reorganização } \\
\text { do calendário escolar do ano letivo de } 2020 \text {, } \\
\text { à luz da Lei Federal } N .^{\circ} 14.040 \text {, de } 18 \text { de }\end{array}$ \\
\hline & \\
\hline
\end{tabular}

Fonte: A autora.

Como visto, a legislação brasileira dispõe apenas orientações sobre o ensino domiciliar por meio de atividades pedagógicas não presenciais mediadas por tecnologias.

Retornando a entrevista, a mesma questão foi realizada com a ETM, a Equipe sinaliza:

Não haverá o Monitoramento e Avaliação do PME este ano porque ficamos sem aulas e isolados. O município não colocou nenhuma ação em prática porque ficamos muito tempo sem aula (Integrante 8).

Assim, o processo de Monitoramento e Avaliação ficou esquecido durante a pandemia, constata-se que esse processo precisa de ações, seja do governo federal, estadual e/ou municipal, que os valorizem.

Diante dos desafios mencionados, percebe-se que a educação escolar está seguindo novos rumos e os sistemas de ensino precisam se adequar para atender as necessidades atuais. É certo que não está sendo fácil, principalmente para as escolas 
públicas, mas é tempo de criar e transformar. É importante frisar que as políticas educacionais precisam ser contínuas e para isso acontecer o Monitoramento e a Avaliação são fundamentais neste processo.

\section{Considerações Finais}

O objetivo desta pesquisa foi analisar o processo de Monitoramento e Avaliação do Plano Municipal de Educação (PME), enquanto política pública educacional, em tempo de crise política e pandemia. Dentre os resultados, destaca- se que o Monitoramento e Avaliação de uma política pública são indispensáveis para o seu sucesso, pois é possível implantar medidas corretivas em relação às decisões tomadas anteriormente, assegurando transparência e legitimidade às metas.

Em relação aos desafios, identificou-se pouca participação da comunidade escolar no Monitoramento e Avaliação, bem como ausência de conhecimento sobre o Plano por parte dos educadores. Desatualização dos dados, ausência de investimentos para cumprir as estratégias, pouco tempo para a construção do Relatório de Monitoramento, falta de envolvimento das pessoas, além de ausência de parceria intersetorial. Em se tratando da pesquisa acadêmica, destaca-se a ausência de trabalhos que discutem o impacto do Golpe de 2016 no processo de Monitoramento e Avaliação das políticas públicas educacionais, bem como análise deste processo em tempo de Covid-19.

Sobre o processo de Monitoramento e Avaliação do Plano Municipal de Educação (PME) pós Golpe de 2016, pontua-se o congelamento de verbas por parte do então presidente Michel Temer, em 2016, limitando a execução de algumas metas e, consequentemente, promovendo instabilidade nas ações do Plano. Em 2020, o Monitoramento e Avaliação do PME em Iguaí/BA foram interrompidos por causa da Covid-19, provocando descontinuidade nas políticas educacionais municipais. A legislação brasileira publicada pós pandemia dispõe apenas orientações sobre o ensino domiciliar por meio de atividades pedagógicas não presenciais mediadas por tecnologias, mas não apresenta nenhuma Lei que garanta o Monitoramento e Avaliação das políticas educacionais em tempo de pandemia. Não há orientações na legislação nacional, muito menos no decreto publicado pela Secretaria de Educação 
de Iguaí/BA, no qual traz orientações sobre a realização de atividades pedagógicas não presenciais (remotas).

Diante do que foi exposto nesta pesquisa, constata-se algumas rupturas e descontinuidades ocorridas nas políticas educacionais desde o Golpe de 2016 e Covid-19. Neste momento desafiador para a educação escolar é necessário que os sistemas educacionais se adequem às novas formas de oferecer a educação escolar por meio do ensino remoto e garanta a aprendizagem dos estudantes.

Em relação ao Monitoramento e Avaliação das políticas públicas educacionais, em especial ao PME, a Secretaria de Educação precisa encontrar alternativas para que este processo aconteça mesmo com o distanciamento social, pois até o momento não há medidas tomadas para garantir que seja realizado.

Assim, propõem-se um acompanhamento permanente de avaliação do PME, com estudos e recolhimento de informações através de ferramentas online, as quais devem compor um banco de dados e contribuir para o alcance das metas.

Advoga-se que o Monitoramento e Avaliação fortalece uma política pública, dá visibilidade e contribui para o seu desenvolvimento através de medidas corretivas.

Assim, ressalta-se a necessidade de aprofundar, em trabalhos futuros, aspectos sobre o impacto do Golpe de 2016 e Covid-19 no processo de Monitoramento e Avaliação de políticas públicas educacionais.

\section{Referências}

ARANDA, M. A. de M; RODRIGUES, E. S. de S; MILITÃO, S. C. N. M. Monitoramento e Avaliação dos Planos Decenais de Educação: a produção do conhecimento no Brasil. DOSSIÊ - Novas e velhas formas de regulação da gestão dos sistemas educacionais. Educar em Revista, Curitiba, v. 36, e69767, 2020. Disponível em: https://www.scielo.br/pdf/er/v36/1984-0411-er-36-e69767.pdf. Acesso em: 02 out. 2020.

ÁVILA, R. I. Palestra: "Rupturas de política econômica e o golpe de 2016".

IFCH-Universidade Federal do Rio Grande do Sul. 2018. Disponível em: https://www.youtube.com/watch?v=rHcgKs8JpMk. Acesso em 28/09/2020.

BARRETO, A. C. F; ROCHA, D. S. Covid 19 e educação: resistências, desafios e (im)possibilidades. Revista Encantar - Educação, Cultura e Sociedade, Bom Jesus da Lapa, v. 2, p. 01-11, jan./dez. 2020.

BOGDAN, R.; BIKLEN, S. Investigação qualitativa em educação. Portugal: Porto Editora, 1994. 
BORGES, M. F. Plano Municipal de Educação (2014-2024): o processo de Monitoramento e a participação do Comitê de Acompanhamento e Avaliação no município de Coração de Maria - Bahia. Mestrado Profissional em Gestão e Tecnologias Aplicadas à Educação: UNEB/Salvador-BA, 2017.

BRASIL. O Plano Municipal de Educação: Caderno de Orientações. Brasília: MEC, 2014.

BRASIL. Substituição das aulas presenciais por aulas em meios digitais enquanto durar a situação de pandemia do Novo Coronavírus - COVID-19. Portaria № 544, de 16 de junho de 2020.

BRASIL. Normatiza procedimentos para a integralização da carga horária mínima do ano letivo afetado pelo estado de calamidade pública e para a reorganização do calendário escolar do ano letivo de 2020, à luz da Lei Federal N. ${ }^{\circ} 14.040$, de 18 de agosto de 2020. Resolução CEE N. ${ }^{\circ}$ 50, DE 09 de novembro de 2020.

BRASIL. Orientações Educacionais para a Realização de Aulas e Atividades Pedagógicas Presenciais e Não Presenciais no contexto da Pandemia. Parecer CNE/CP n' 11/2020 de 07/07/2020.

BRASIL. Diretrizes Nacionais para a implementação dos dispositivos da Lei $n^{0} 14.040$, de 18 de agosto de 2020, que estabelece normas educacionais excepcionais a serem adotadas durante o estado de calamidade pública reconhecido pelo Decreto Legislativo $\mathrm{n}^{\circ} 6$, de 20 de março de 2020. Parecer CNE/CP n 15 de 06/10//2020.

BRASIL. Normatiza procedimentos para a integralização da carga horária mínima do ano letivo afetado pelo estado de calamidade pública e para a reorganização do calendário escolar do ano letivo de 2020, à luz da Lei Federal N. ${ }^{\circ} 14.040$, de 18 de agosto de 2020. Parecer CEE n 99/2020 de 10/11/2020.

BRASIL. Plano Nacional de Educação. 2014.

DOURADO, L. F. Avaliação do Plano Nacional de Educação 2001-2009: questões estruturais e conjunturais de uma política. Educação e Sociedade, Campinas, v. 31, n. 112, p. 675-705, jul./set. 2010. Disponível em: http://www.scielo.br/pdf/es/v31n112/03. Acesso em: 02 out. 2020.

IGUAÍ. Plano Municipal de Educação. Secretaria Municipal de Educação. 2015.

IGUAÍ. Relatório de Monitoramento e Documento de Avaliação. 2017. 2018. 2019.

IGUAÍ. Decreto 004/2020 de 18 de março de 2020 - Estabelece medidas preventivas a serem adotadas no Município de Iguaí, objetivando o enfrentamento da pandemia ocasionada pelo novo Coronavírus (COVID19), e dá outras providências.

IGUAÍ. Decreto N 50/2020, de 31 de Julho de 2020 - Dispõe sobre a realização de atividades pedagógicas não presenciais (remotas), no âmbito da Rede Pública Municipal de Educação. 
LOMBARDI, J. C.; LIMA, M. R. Golpes de estado e educação no Brasil: a perpetuação da farsa. In: KRAWCZYK, N; LOMBARDI, J. C. (Org). O Golpe de 2016 e educação no Brasil. $1^{a}$ ed. eletrônica. Uberlândia: Editora Navegando, 2018.

MENDONÇA, I; GOMES, M. F. Grupo focal: instrumento de coleta de dados na pesquisa em educação. Cad. Ed. Tec. Soc., v. 10, n. 1, p. 52-62, 2017.

MENEZES, A. M. F. Ciclo das políticas públicas. In: CAMPOS, M. F. H; LEÃO, J. A. C; NETO, J. F. B. (Orgs). Ciclo de políticas públicas: sistematização de experiências. Curitiba: Editora CRV, 2019.

NETO, A. C.; CASTRO, A. M. D. A.; GARCIA, L. T. S. Plano Municipal de Educação: elaboração, acompanhamento e avaliação no contexto do PAR. Revista Brasileira de Política e Administração da Educação, v. 32, n. 1, p. 047 - 067 jan./abr. 2016.

OLIVEIRA, A. F. Políticas públicas educacionais: conceito e contextualização numa perspectiva didática. In: OLIVEIRA, Adão F. de; PIZZIO, Alex; FRANÇA George (Orgs.). Fronteiras da educação: desigualdades, tecnologias e políticas. Goiás: Editora da PUC, 2010. p. 93-99.

ODILLA, F. 5 anos depois, o que aconteceu com as reivindicações dos protestos que pararam o Brasil em junho de 2013? Reportagem no site da BBC News Brasil em Londres, no dia 09 de junho de 2018.

ORSO, P. J. Reformas educacionais em tempos de golpe ou como avançar andando para trás. In: LUCENA, C; PREVITALI, F. S.; LUCENA, L. (Org). A crise da democracia brasileira. $1^{a}$ ed. eletrônica. Uberlândia: Editora Navegando, 2017.

RUA, M. G. Políticas públicas (3a ed.) - Florianópolis : Departamento de Ciências da Administração / UFSC; [Brasília]: CAPES : UAB, 2014.

SAVIANI, D. A crise política no Brasil: o golpe e o papel da educação brasileira na resistência e na transformação. In: PREVITALI, Lucena, C; PREVITALI, F. S. (Orgs.). A crise da democracia brasileira. $1^{a}$ ed. eletrônica. Uberlândia: Editora Navegando, 2017.

SAVIANI, D. A crise política e o papel da educação na resistência ao golpe de 2016 no Brasil. IN: KRAWCZYK, N; LOMBARDI, J. C. (Orgs.). O Golpe de 2016 e educação no Brasil. $1^{a}$ ed. Eletrônica. Uberlândia: Editora Navegando, 2018.

SILVA, M. O. S. (Org.). Avaliação de políticas e programas sociais: teoria e prática. São Paulo: Veras, 2001.

TEMER, M. Plano a ponte para o futuro. 2015. Disponível em:https://www.fundacaoulysses.org.br/wp-content/uploads/2016/11/UMA-PONTEPARA -O-FUTURO. pdf. Acesso em: 08 de outubro de 2020. 


\section{Edcleide da Silva Pereira Novais}

Mestre em Educação em Ciências. Pedagoga e licenciada em Artes com especialização em Educação Infantil e Políticas Públicas e Gestão da Educação. Tem experiência na Educação Básica e Ensino Superior. Pesquisa os seguintes temas: Educação do Campo, Políticas Públicas, Gestão Educacional, PME e PAR.

\section{Daelcio Ferreira Campos Mendonça}

Doutor em Educação (UFBA). Mestre em Educação (UFBA). Especialista em Neuropsicologia (IBPEX). Graduado em Pedagogia (UFBA). Professor da Universidade Estadual do Sudoeste da Bahia (UESB-Itapetinga). Coordenador do Seminário de Políticas Públicas e Gestão Educacional. Coordenador da Especialização em Políticas Públicas e Gestão Educacional e Coordenador do Observatório de Políticas Públicas e Gestão Educacional-UESB-Itapetinga. 